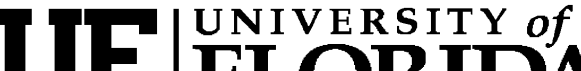 FLORIDA \\ IFAS Extension
}

\section{Using Seasonal Climate Variability Forecasts: Crop Yield Risk ${ }^{1}$}

Clyde W. Fraisse, Joel O. Paz, and Charles M. Brown²

\section{Introduction}

The bottom line in production agriculture is crop yield. Improving crop yield is the subject of continual study as researchers produce new plant varieties and agrochemicals and seek out the best management practices. Producers use these science-based tools to overcome challenges due to factors such as soil type and quality presented by their location.

Yet, producers are often at the mercy of natural forces which they cannot control, especially changes in rainfall from season to season and year to year ("seasonal climate variability"). In fact, most U.S. crop failures are associated with either too little or too much rainfall (Ibarra and Hewitt, 1999).

Variations from the "normal" climate can set the stage for other kinds of production risks, such as pest and disease incidence. Some weather patterns, such as high temperatures, high humidity, or higher than normal rainfall, can raise the chances of fungal diseases. They can also improve conditions for insects and other pests that spread disease among plants and fields (Fraisse et al., 2006).
In the U.S., yields tend to be most dependable in the central Corn Belt, where soils are deep and rainfall dependable (Harwood et al., 1999). Nevertheless, modern agriculture is practiced successfully in all parts of the United States. In the Southeast, there is plenty of rain --- annual rainfall averages around 1,400 $\mathrm{mm}$ (55 inches) --- and that should ensure good crop yields. However, other factors can reduce the usefulness of available rainfall. For example, in certain areas, such as the Florida panhandle, yields can vary substantially because soils have a low water-holding capacity, and there is always a potential for poor rainfall distribution or low rainfall amounts during critical phases of crop growth.

If producers had better tools for understanding how rainfall might vary from normal during upcoming seasons, they would be better equipped to adjust their practices to ensure the best yield possible. Fortunately, much progress has been made in understanding what causes variations in seasonal climate, and this progress has allowed climate researchers to create tools that are available on-line. This publication can help producers access these tools

1. This document is CIR1498, one of a series of the Agricultural and Biological Engineering Department, Florida Cooperative Extension Service, Institute of Food and Sciences, University of Florida. Published January 2007. To view the full range of publications available from the Florida Cooperative Extension Service, please visit the EDIS website at http://edis.ifas.ufl.edu.

2. Clyde W. Fraisse, Assistant Extension Scientist, Agricultural and Biological Engineering Department, University of Florida; Joel O. Paz, Public Service Assistant, Department of Biological and Agricultural Engineering, University of Georgia; and Charles M. Brown, Coordinator for Information/Publication Services, Agricultural and Biological Engineering Department, University of Florida.

The Institute of Food and Agricultural Sciences (IFAS) is an Equal Opportunity Institution authorized to provide research, educational information and other services only to individuals and institutions that function with non-discrimination with respect to race, creed, color, religion, age, disability, sex, sexual orientation, marital status, national origin, political opinions or affiliations. U.S. Department of Agriculture, Cooperative Extension Service, University of Florida, IFAS, Florida A. \& M. University Cooperative Extension Program, and Boards of County Commissioners Cooperating. Millie Ferrer-Chancy, Interim Dean 
and use them to better understand crop yield risks associated with climate variability.

Specifically, in this report, we will explain how to use historical crop yield information available through the AgClimate website (www.agclimate.org) to understand yield risk for specific crops in Alabama, Florida, and Georgia. The crop yield tools are just one set of many sources of information for producers that are available through the AgClimate website.

\section{Major Source of Climate Variability}

The strongest driver of year-to-year climate variations around the world is called the El Niño Southern Oscillation (ENSO) phenomenon (Ropelewski and Halpert, 1996). This phenomenon is known best as an increase or decrease in the sea surface temperature in the eastern equatorial Pacific Ocean. Remarkably, the temperature of this region of the ocean has significant influence on climate, and therefore crop production, in many parts of the world, including Southeast Africa, South Asia, East Asia, East Australia, the Pacific Northwest, and coastal areas of South America. Most importantly for our purposes, El Niño has an important and predictable influence on climate in the Southeast United States.

When sea surface temperature (SST) is higher than normal in this region of the eastern Pacific, the phenomenon is referred as to El Niño. Warmer seas cause the atmosphere above this area to be warmer and results in more moisture being lifted higher into the atmosphere ("convective activity"). This moisture can then fall as rain showers or thunderstorms. The El Niño phenomenon can also affect the trade winds, which normally blow from east to west in the eastern Pacific, by causing them to decrease in strength (Cane, 2001) or even reverse direction and blow from west to east.

When the sea surface temperature is lower than normal, the phenomenon is referred to as La Niña. La Niña events strengthen the east-to-west flow of equatorial trade winds. This literally stirs the ocean so that colder water is brought up from the ocean's floor.
About half the time, sea surface temperatures are close to normal. During these times, there is neither El Niño nor La Niña present in the Pacific. This called a Neutral phase. Under Neutral conditions, trade winds blow normally from east to west near the Equator in the Pacific Ocean.

Research has demonstrated that ENSO exerts a substantial influence on the climate of the Southeast U.S. In El Niño years, the Southeast overall tends to be cooler, and in La Niña years, it tends to be warmer between October and April (Kiladis and Diaz, 1989; Sittel, 1994, Mearns et al., 2003). The influence of the ENSO phenomenon tends to be less consistent across the region, but in El Niño years, much of the Southeast will be wetter, and in La Niña years, drier during these months. The ENSO effect in the region is strongest in the fall and winter months; there are some indications that La Niña summers tend to be slightly wetter than normal (Sittel, 1994).

A study of total production value and its three components --- yield, area harvested, and price --demonstrated the impact of climate on crop yield (Hansen et al 1998). Researchers included data for a 35-year period, from 1960-1995. The study examined ENSO phases, quarterly SST, and their possible influence on the production of six crops in four southeastern states (peanut, tomato, cotton, tobacco, corn and soybean in Alabama, Florida, Georgia and South Carolina).

The study showed that the ENSO phase had a very significant effect on the yields of corn and tobacco, the areas of soybean and cotton harvested, and the production values of corn, soybean, peanut and tobacco. ENSO phases explained an average shift of $\$ 212$ million, or $25.9 \%$, of the value of corn. It was also shown that changes in SST caused significant changes in yield for corn, soybean and cotton, and value for peanut across the region. Also, peanut and tobacco yields, and tomato and soybean values in particular states were significantly affected.

\section{AgClimate.org}

The research described in the previous section has been combined with other work to create a Web-based system called AgClimate that producers in the Southeast can use to analyze risks associated 
with climate variation. By using this decision support tool, producers can better understand the risks they face due to climate variations and plan accordingly to reduce the impact of those risks. Through AgClimate, producers can access forecasts, historical yield information, and a variety of tools for evaluating risk.

AgClimate was developed by the Southeast Climate Consortium (SECC) in partnership with the Cooperative State Extension Service. The SECC is a coalition of six universities: Florida State University, University of Florida, University of Miami, University of Georgia, Auburn University, and University of Alabama-Huntsville. AgClimate and the other programs of the SECC are designed around broad themes of product assessment and evaluation, program evaluation, and economic analysis. AgClimate brings together research done in the fields of climate, forestry, agricultural risk, extension, and natural resources and the environment. Information available in AgClimate includes climate forecasts combined with risk management tools and information for selected crops, forestry, pasture, and livestock.

\section{Crop Yield Risk Tools in AgClimate}

Production or yield risk comes from the unpredictable nature of natural factors such as weather or the performance of crops under the pressure of diseases and pests or other unforeseen factors. Risk also comes from market-driven factors, such as institutional and financial risks. Together, all these risks can have a significant affect on the profitability and long-term sustainability of the farm enterprise. Producers can choose from several strategies to help minimize the impacts of adverse climate on crop yield. A few od these choices are: changing crops or varieties; changing planting dates; and investing in irrigation equipment. Nevertheless, the process of minimizing yield risk must include an understanding or quantification of the risk involved, the ability to simulate "what-if" scenarios for evaluating potential strategies, and real-time information and weather monitoring.

Figure 1 illustrates the various categories of information available in AgClimate and how they work together to give producers a new understanding of crop yield risk. Information categories include:
- Climate Forecast

- Crop Models

- Commodity Outloooks

- Historical Weather

- Historical Yield (Past Yield Records)

For example, past yield records can be studied alongside historical weather information to help producers understand the effects of ENSO phases on crop yield. This kind of analysis can give producers insight into the production history of their own operation and that of their area. Also, SECC researchers are working to develop applications based on crop models, which take into account climate forecasts, and can be used for evaluating alternative management practices, such as planting dates, crops and varieties. Through AgClimate, producers will eventually have a means to study the future yield potential of a selected location under different climate scenarios and management practices with the click of a mouse.

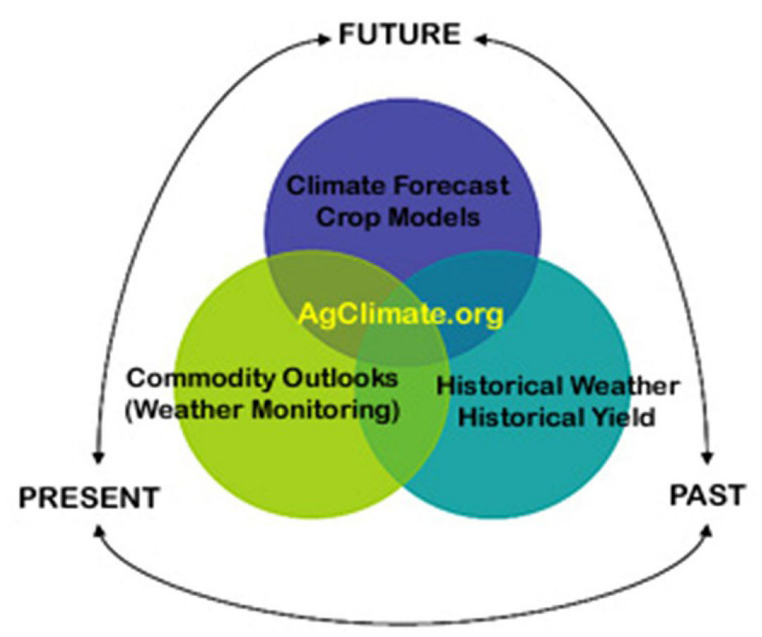

Figure 1. Framework for crop yield risk analysis in AgClimate

Once a season starts and the crop is planted (present), producers can minimize the risks associated with climate variability by monitoring real-time weather and taking the necessary actions when possible. To provide real-time weather information, AgClimate links to agricultural weather networks in Florida (Florida Automated Weather 
Network, FAWN) and Georgia (Georgia Automated

Environmental Monitoring Network).

Through AgClimate, climate and agricultural outlooks released throughout the year provide producers with updates on current conditions and summary interpretations of the latest climate forecast. In the case of agricultural outlooks, potential impacts on a variety of crops are listed and adaptation strategies are discussed. Agricultural outlooks are produced by Extension climate specialists in partnership with commodity specialists.

\section{County Historic Crop Yield Tool}

AgClimate gives users access to a vast library of data about historical yields at the county level. This information can provide a valuable perspective of the possible influence of ENSO phases on crop yields. In AgClimate, historical yield data is drawn from the records of USDA's National Agricultural Statistics Service (NASS).

\section{How to Access the County Historic Crop Yield Tool}

On the AgClimate homepage, select "AgClimate Tools" from the menu on the left side of the page. A submenu and a new page will appear. Select "Crop Yield" either on the submenu or on the new page. A new page will appear with a selection of climate tools. Select "County Historic Crop Yield" and a new page will appear with an options menu on the left and a yield table and historical yield plot on the right. These features are shown in figure 2, a screen shot of the AgClimate County Historic Yield Tool.

\section{How to Use the County Historic Crop Yield Tool}

The user controls what is displayed in the table and graph at the right by making selections on the left-hand menu. Users make five selections:

\footnotetext{
- State

- County

- Crop
}

- Yield Display or Residual Display

- Optional: Add Rain or Temperature Averages to the Display

Crops currently available include corn, cotton, oats, peanuts, potato, rye, soybean, sugarcane, tobacco, and winter wheat.

When the user selects Yield Display and completes the other choices, AgClimate automatically creates a plot on the right-hand side of the page of crop yield with a trend line. Above the plot, is a table giving basic yield statistics for the users selection, including average yield, standard deviation, minimum yield, maximum yield, and median yield. These five statistics are given for Neutral years, El Nino years, La Nina years, and All years.

Users can also compare yields in different counties in the same state by selecting more than one county in the pull-down menu. Figure 2 shows a plot of the corn yields in two Florida counties, Alachua and Jackson. When multiple counties are selected, it is not possible to add rain or temperature averages to the display.

To the upper right of the summary table is a button that reads "Yield Data." By clicking on this button, users can get a table showing the specific yield data for every year in all selected counties.

When viewing yield data, users should be aware that climate variability is not the only factor that influences the change in yield over time. Other factors, such as technological advances (improved varieties or management, shifts from rain-fed to irrigated production) and price cycles, also affect historical data. These longer range effects are shown by the trend line. The seasonal effect of climate is seen by the shorter term changes around the trend line on the historical yield plot.

Users can focus on seasonal climate effects and remove long-term effects on yield data by switching to the Residual Display. The residual for any year is the percent by which the yield for that year was higher or lower than the expected yield (trend line) value for that year. The residuals show whether the yield was 
better or worse than would have been expected.

Residuals are plotted on a percentage scale.

The plot of residuals also includes a small bar graph in the top right corner of the page displaying average residuals for each ENSO phase.

\section{Regional Historic Crop Yield Tool}

Users can also view average residuals for the tri-state region in a map format. This AgClimate feature provides a regional overview of potential production risks for each ENSO phase (figure 4).

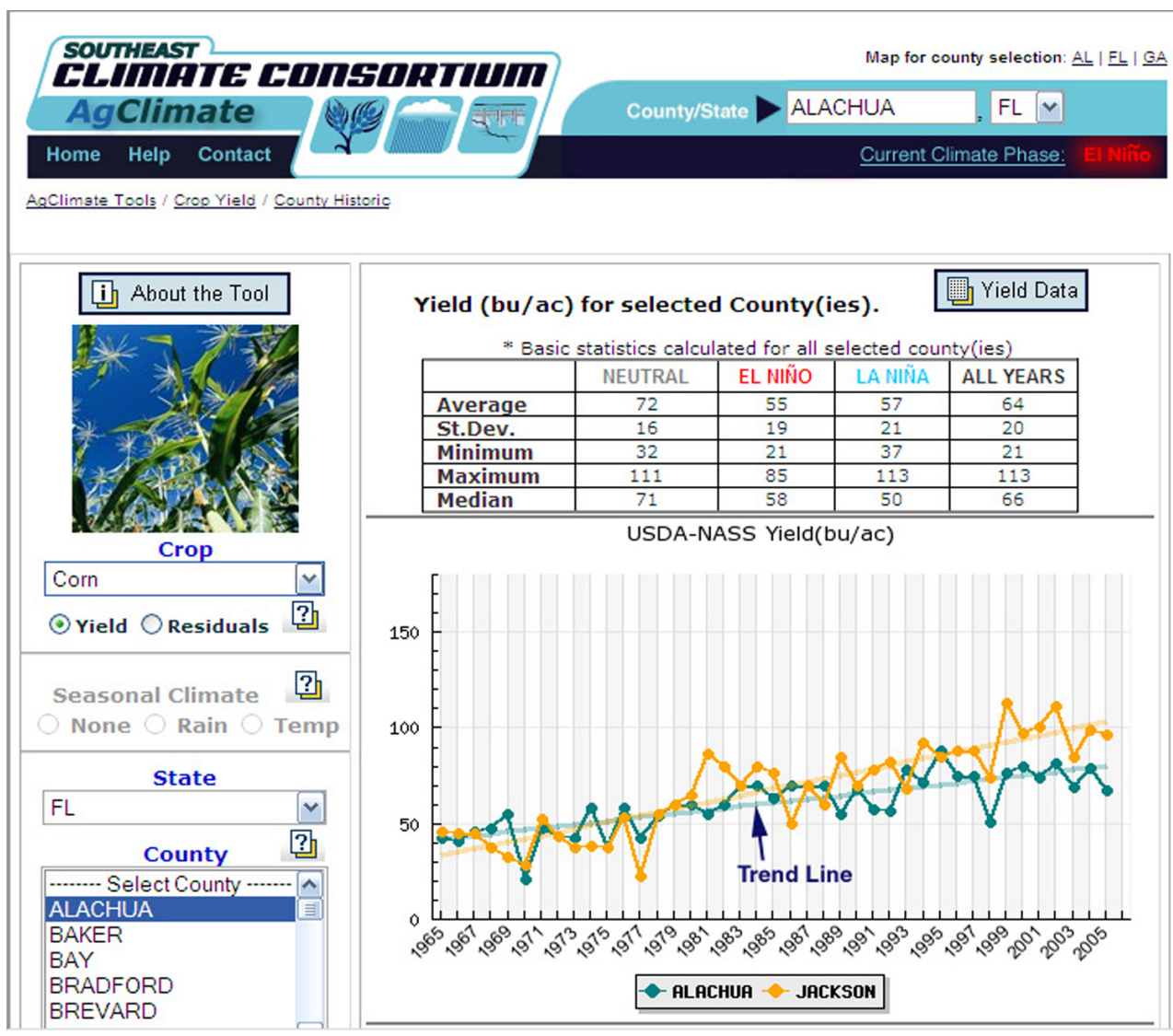

Figure 2. Corn historical yield time series for two counties in Florida

\section{Interpreting the Results}

In figure 3, the bar graph in the upper right shows that corn yields are, on average, $11.6 \%$ lower during El Niño years. Notice that the range of variability after the mid 80s is smaller, suggesting that yields have become more stable in the last 20 years.

Also notice the yield display (figure 2) that during the last 15 years or so, corn yields in Jackson County (yellow line) have improved in relation to Alachua County yields. This could be the result of better management practices, including the increase of irrigated acreage.
However, regional averages are a very general overview and should be followed up using the County Historic Yield Tool described above.

\section{How to Access the Regional Historic Crop Yield Tool}

Beginning on the AgClimate homepage, select "AgClimate Tools" from the menu on the left side of the page. A submenu and a new page will appear. Select "Crop Yield" either on the submenu or on the new page. A new page will appear with a selection of climate tools. Select "Regional Historic Crop Yield" and a map will be displayed showing color-coded average crop yield residuals for each county in the region. Buttons on the left allow the user to select a map for any ENSO phase. 


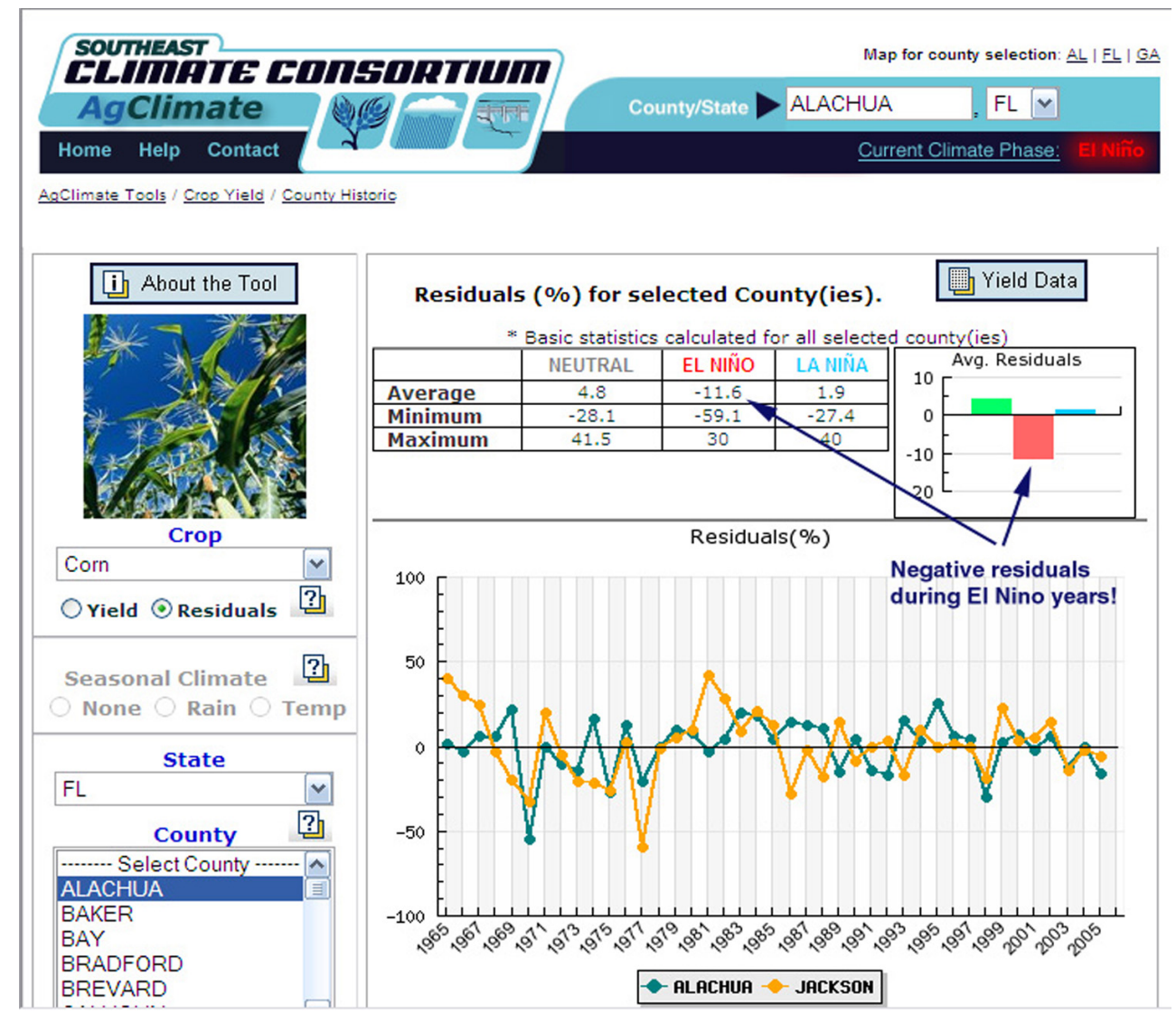

Figure 3. Plot of corn yield residuals for two counties in Florida

\section{How to Use the Regional Historic Crop Yield Tool}

An example of a regional residual map is shown in figure 4. This map shows the average soybean yield residuals for El Niño years. Notice that average soybean residuals (and therefore, yields) tend to be lower than average in the northern regions of Alabama and Georgia during El Niño years. Based on this information, producers in those regions might consider better crop insurance coverage during years when an El Niño is taking place.

\section{Climate and Commodity Outlooks}

The main purpose in this report has been to describe the use of historical crop yield to estimate crop yield risk. However, there are many other sources of information on the AgClimate website. Producers will want to make use of both the general climate outlooks and agricultural outlooks released through AgClimate. These outlooks are released four times a year.
The main purpose of the outlooks is to summarize current conditions and expected climate conditions during the next two or three months. Climate outlooks are released in order to match producers decision calendar such as early spring before planting, mid-summer during crop development stages, and mid to late fall, when citrus and winter vegetable producers are concerned about freeze forecasts.

Agricultural outlooks have been recently added to the suite of products in AgClimate. The main purpose of agriculture outlooks is to discuss potential impacts and adaptation strategies for the main crops in the region.

\section{References}

Cane, M. A. 2001. Understanding and predicting the world's climate system. In: Impacts of El Niño and climate variability on agriculture. American Society of Agronomy (ASA) Special Publication 63. 


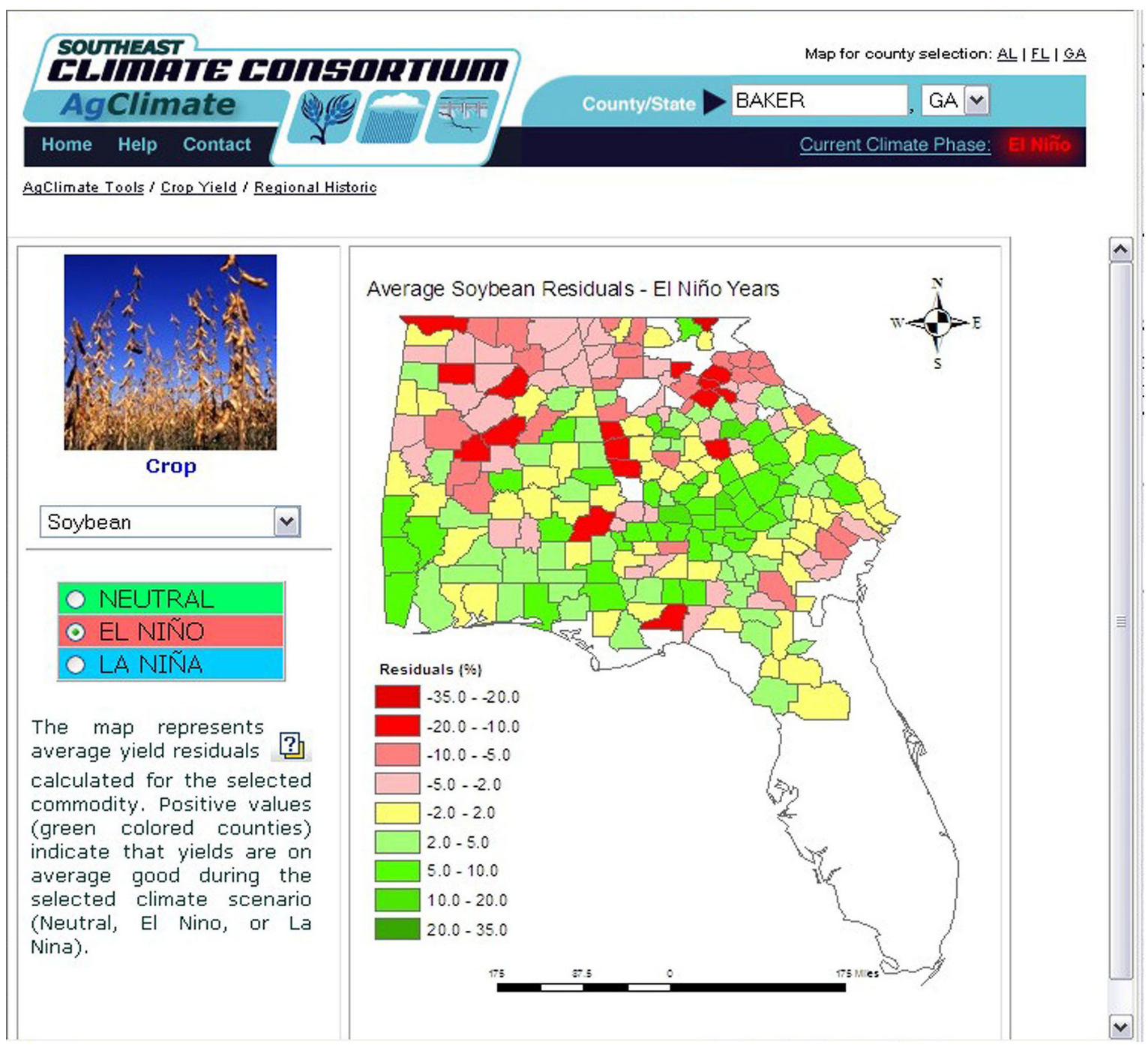

Figure 4. Regional map of average soybean yield residuals during El Niño years

Fraisse, C. W., Breuer N., Bellow, J. G., Cabrera, V., Hatch, U., Hoogenboom, G., Ingram, K., Jones, J. W., O'Brien, J., Paz, J., and Zierden, D. 2006. AgClimate: A climate forecast information system for agricultural risk management in the southeastern USA. Computers \& Electronics in Agriculture 53(1):13-27.

Hansen, J. W., Hodges, A. W., and Jones, J. W. 1998. ENSO influences on agriculture in the Southeastern U.S. Journal of Climate 11(3):404-411.

Harwood, J., Heifner, R., Coble, K., Perry, J., and Somwaru, A. 1999. Managing risk in farming: concepts, research, and analysis. United States Dept. of Agriculture, Economic Research Service (AER-774).
Ibarra, R. and Hewitt, T. 1999. Utilizing crop insurance to reduce production risk. Institute of Food and Agricultural Sciences (IFAS Publication FE-198), Florida Cooperative Extension Service. Gainesville, Florida.

Kiladis, G. N. and Diaz, H. F. 1989. Global climatic anomalies associated with extremes in the Southern Oscillation. Journal of Climate 2:1069-1090.

Mearns, L. O., Giorgi, F., McDaniel, L., and Shields, C. 2003. Climate scenarios for the southeastern U.S. based on regional model simulations. Climatic Change 60:7-35.

Ropelewski, C. F. and Halpert, M. S. 1996. Quantifying southern oscillation: precipitation relationships. Journal of Climate 9:1043-1059. 
Sittel, M.C. 1994. Marginal probabilities of the extremes of ENSO events for temperature and precipitation in the Southeastern United States, Tech. Rep. 94-1. Center for Ocean-Atmospheric Studies, Florida State University. Tallahassee, Florida. 